\title{
The reliability and validity of the PALOC-s: a post- acute level of consciousness scale for assessment of young patients with prolonged disturbed consciousness after brain injury
}

Citation for published version (APA):

Eilander, H. J., van de Wiel, M., Wijers, M., van Heugten, C. M., Buljevac, D., Lavrijsen, J. C., Hoenderdaal, P. L., de Letter-van der Heide, L., Wijnen, V. J., Scheirs, J. G., de Kort, P. L. M., \& Prevo, A. J. H. (2009). The reliability and validity of the PALOC-s: a post-acute level of consciousness scale for assessment of young patients with prolonged disturbed consciousness after brain injury.

Neuropsychological Rehabilitation, 19(1), 1-27. https://doi.org/10.1080/09602010701694822

Document status and date:

Published: 01/01/2009

DOI:

$10.1080 / 09602010701694822$

Document Version:

Publisher's PDF, also known as Version of record

Document license:

Taverne

Please check the document version of this publication:

- A submitted manuscript is the version of the article upon submission and before peer-review. There can be important differences between the submitted version and the official published version of record. People interested in the research are advised to contact the author for the final version of the publication, or visit the DOI to the publisher's website.

- The final author version and the galley proof are versions of the publication after peer review.

- The final published version features the final layout of the paper including the volume, issue and page numbers.

Link to publication

\footnotetext{
General rights rights.

- You may freely distribute the URL identifying the publication in the public portal. please follow below link for the End User Agreement:

www.umlib.nl/taverne-license

Take down policy

If you believe that this document breaches copyright please contact us at:

repository@maastrichtuniversity.nl

providing details and we will investigate your claim.
}

Copyright and moral rights for the publications made accessible in the public portal are retained by the authors and/or other copyright owners and it is a condition of accessing publications that users recognise and abide by the legal requirements associated with these

- Users may download and print one copy of any publication from the public portal for the purpose of private study or research.

- You may not further distribute the material or use it for any profit-making activity or commercial gain

If the publication is distributed under the terms of Article 25fa of the Dutch Copyright Act, indicated by the "Taverne" license above, 


\section{The reliability and validity of the PALOC-s: A Post- Acute Level of Consciousness scale for assessment of young patients with prolonged disturbed consciousness after brain injury}

H. J. Eilander, M. van de Wiel, M. Wijers, C. M. van Heugten , D. Buljevac , J. C. M. Lavrijsen , P. L. Hoenderdaal , L. de Letter-van der Heide , V. J. M. Wijnen , J. G. M. Scheirs , P. L. M. de Kort \& A. J. H. Prevo

To cite this article: H. J. Eilander , M. van de Wiel , M. Wijers , C. M. van Heugten , D. Buljevac , J. C. M. Lavrijsen , P. L. Hoenderdaal , L. de Letter-van der Heide, V. J. M. Wijnen, J. G. M. Scheirs , P. L. M. de Kort \& A. J. H. Prevo (2009) The reliability and validity of the PALOC-s: A Post-Acute Level of Consciousness scale for assessment of young patients with prolonged disturbed consciousness after brain injury, Neuropsychological Rehabilitation, 19:1, 1-27, DOI: 10.1080/09602010701694822

To link to this article: https://doi.org/10.1080/09602010701694822

Published online: 18 Dec 2008.

山 Article views: 335
Submit your article to this journal $\sqsubset$

Citing articles: 4 View citing articles $\left[\begin{array}{c}0 \\ 0\end{array}\right.$ 


\section{The reliability and validity of the PALOC-s: A Post-Acute Level of Consciousness scale for assessment of young patients with prolonged disturbed consciousness after brain injury}

H. J. Eilander ${ }^{1}$, M. van de Wiel ${ }^{1,2}$, M. Wijers ${ }^{1,2}$, C. M. van Heugten ${ }^{1,3,6}$ D. Buljevac ${ }^{1}$, J. C. M. Lavrijsen ${ }^{4}$, P. L. Hoenderdaal, L. de Letter-van der Heide ${ }^{1}$, V. J. M.Wijnen ${ }^{1,2}$, J. G. M. Scheirs ${ }^{2}$, P. L. M. de Kort ${ }^{5}$, and A. J. H. Prevo ${ }^{6,7}$

${ }^{1}$ Rehabilitation Centre Leijpark, Division Research, Tilburg, The Netherlands, ${ }^{2}$ Tilburg University, Faculty of Social Sciences, Department of Psychology and Health, Tilburg, The Netherlands, ${ }^{3}$ Maastricht University, Institute Brain and Behaviour, Maastricht, The Netherlands, ${ }^{4}$ Radboud University Nijmegen Medical Centre, Department of Nursing Home Medicine, Nijmegen, The Netherlands,

${ }^{5}$ St. Elisabeth Hospital, Division Neurology, Tilburg, The Netherlands, ${ }^{6}$ Rehabilitation Centre De Hoogstraat, Utrecht, The Netherlands, ${ }^{7}$ Rudolf Magnus Institute of Neuroscience, UMC Utrecht, Utrecht, The Netherlands

Correspondence should be addressed to H. J. Eilander, Rehabilitation Centre Leijpark, P.O. Box 5022, 5004 EA Tilburg, The Netherlands. E-mail: H.J.Eilander@hccnet.nl

This study is part of a larger evaluation project of the rehabilitation programme "Early intensive neurorehabilitation for children and young adults in a vegetative or minimally conscious state after severe brain injury". The study was funded through grants from: Stichting Centraal Fonds RVVZ, Johanna Kinderfonds, Stichting Bio Kinderrevalidatie, CZ groep Zorgverzekeringen, Zorgverzekeraar VGZ, Zorg en zekerheid, and Hersenstichting Nederland. Financial support, given by C. Gerritsen, was essential for starting and continuation of the overall project.

The study was approved by the medical ethical committee (METOPP). We are grateful to all members (H. van Daal, P. L. Hoenderdaal, J. C. M. Lavrijsen, A. I. R. Maas, A. J. H. Prevo, H. Stroink, A. J. J. M. Vingerhoets and H. van der Vlugt) of the scientific advisory committee for their contribution to the design of this study. We also are very grateful to several trainees who assisted in the examination of the patients.

(C) 2008 Psychology Press, an imprint of the Taylor \& Francis Group, an Informa business http://www.psypress.com/neurorehab

DOI: $10.1080 / 09602010701694822$ 
The objective of the study was the validation of the Post-Acute Level of Consciousness scale (PALOC-s) for use in assessing levels of consciousness of severe brain injured patients in a vegetative state or in a minimally conscious state. A cohort of 44 successively admitted patients (between 2 and 25 years of age), who were treated in an early intensive neurorehabilitation programme, were included in the study. Each patient was examined, using the Western Neuro Sensory Stimulation Profile (WNSSP) and the Disability Rating Scale (DRS), once every two weeks resulting in 327 examinations (all videotaped). To determine the reliability of the PALOC-s, six observers rated one videotape of each patient. One of the observers rated the same tapes a second time, 3-4 months later. Validity was determined by correlating 100 ratings of one observer with the scores on the WNSSP and the DRS. To determine the responsiveness of the PALOC-s, the size of change between the scores of the first and last examinations was calculated. The inter-observer correlations and agreement scores varied between .82 and .95 . The intra-observer correlation and agreement scores varied between .94 and .96 . Correlations with the WNSSP varied between .88 and .93 , and with the DRS between .75 and .88 . The responsiveness was significantly high $(t=8.2)$, with a standardised effect size of 1.30 .

It is concluded that the PALOC-s is a reliable, valid, and responsive observation instrument provided it is administered after a structured assessment by an experienced and trained clinician. The PALOC-s is feasible for use in clinical management, as well as in outcome research.

Keywords: Level of consciousness; Minimally conscious state; Reliability; Responsiveness; Severe brain injury; Validity; Vegetative state.

\section{INTRODUCTION}

Severe brain injury as defined by a score of eight or less on the Glasgow Coma Scale (GCS) (Teasdale \& Jennett, 1974) is generally characterised by a prolonged loss of consciousness, defined as coma, a state in which the eyes of the patient are closed. The mere opening of the eyes does not necessarily signify the return of consciousness. This unconscious state, according to the initial description of Jennett and Plum (1972), is generally called the vegetative state (VS). Ever since its introduction, the term "vegetative state" has given rise to discussions. These discussions concern the name of the syndrome, the nature, the probable duration, the treatment that should or should not be given, the existence of a possible variant for children and so on (American Congress of Rehabilitation Medicine, 1995; Campbell, 1984; Gezondheidsraad, 1994; Giacino \& Zasler, 1995; Lavrijsen et al., 2003; Royal College of Physicians, 2003; Shewmon, 2000). One of the most discussed topics concerns the variability of the observed symptoms (Andrews, 1996a). Some patients are completely motionless, while others can make 
all kinds of automatic movements. Some patients show emotions, often in reaction to stimuli, while others show no reaction at all. The introduction of the concepts of the minimally responsive state (MRS) by the American Congress of Rehabilitation Medicine (1995), the low awareness state (LAS) by the International Working Party on the Vegetative State (Andrews, 1996b) and the minimally conscious state (MCS) by the Aspen Neurobehavioural Conference (Giacino et al., 1997), offered (new) possibilities to describe unconsciousness from coma to full consciousness including all levels in between. The key feature of all three concepts is the introduction of a level of consciousness that is neither comatose nor vegetative nor fully conscious. The introduction of such a state makes it easier to monitor the course of recovery from coma to full consciousness.

Patients with severe brain injury do not recover suddenly from the comatose or vegetative state into full consciousness. When they show any signs of recovery, there is a broad range of slight behavioural changes, diverse and inconsistent awareness of themselves or their surroundings, and increasing reactivity and cognitive understanding. It is obvious that different patient capabilities require different treatments (Andrews, 1996b; Ng \& Chua, 2005; Whyte \& Glenn, 1986). Recently, the need for accurate differential diagnosis has been identified as the essential first step in clinical management of patients with consciousness disorders (Giacino \& Kalmar, 2005). In the last three decades, different techniques and scales have been developed to monitor the possible recovery in the level of consciousness of patients (Ansell, Keenan, \& de la Rocha, 1989; Borer-Alafi, Gil, Sazbon, \& Korn, 2002; Freeman, 1996; Giacino, Kezmarsky, Deluca, \& Cicerone, 1991; GillThwaites, 1997; Hagen, Malkmus, \& Durham, 1972; Jennett \& Bond, 1975; Rader \& Ellis, 1994; Rappaport, Dougherty, \& Kelting, 1992; Shiel et al., 2000). Some of these scales are not very sensitive to slight changes in responsiveness of vegetative or minimally conscious patients. Others are aimed at monitoring the depth of the loss of consciousness in the acute phase, such as the Glasgow Coma Scale (GCS) (Teasdale \& Jennett, 1974), or have been designed to measure gradual changes in the level of cognitive recovery of patients who are in a diminished state of consciousness, such as the Western Neuro Sensory Stimulation Profile (WNSSP; Ansell et al., 1989). The Rancho Los Amigos Levels of Cognitive Functioning (RLA; Hagen et al., 1972), which is commonly used in evaluating the rehabilitation of patients with traumatic brain injury, focuses on cognitive and behavioural recovery. Some scales focus on reactions to specific sensory stimuli, such as the Sensory Modality Assessment Rehabilitation Technique (SMART; Gill-Thwaites, 1997) and the Sensory Stimulation Assessment Measure (Rader \& Ellis, 1994), while other methods rely on qualitatively described behavioural aspects, such as the Wessex Head Injury Matrix (WHIM; Shiel et al., 2000). 
However, none of these scales was developed to distinguish between VS and MCS, including the possible sublevels within these two states.

In order to evaluate the effect of a treatment programme aimed at the recovery of consciousness (Eilander, Wijnen, Scheirs, de Kort, \& Prevo, 2005), an observation scale more precisely measuring the levels of consciousness was needed. This resulted in the development of the Post-Acute Level of Consciousness scale, the PALOC-s. The observation scale consists of eight different (sub)levels of consciousness, from coma through vegetative and minimally conscious states to full consciousness (see Appendix I). If the PALOC-s appears to be a reliable and valid instrument, its applicability can possibly be extended to the work of others aimed at developing and evaluating treatment programmes for unconscious patients.

In this study, the reliability, validity, and responsiveness of the PALOC-s were investigated in a cohort of children, adolescents, and young adults. The reliability and the responsiveness, first of a draft version of the PALOC-s and then for the final version, were determined.

\section{METHOD}

\section{Participants}

All 44 patients who participated were admitted to an early intensive neurorehabilitation programme (EINP) in the Rehabilitation Centre Leijpark in Tilburg, the Netherlands, between January 2001 and September 2003. Admission criteria for EINP were: severe brain injury (initial GCS at time of injury $\leq 8$ ), between 2 and 25 years of age, in VS or MCS, independent of life support systems such as artificial respiration, and admission within 6 months after a traumatic or vascular injury or 3 months after an anoxic injury. No patients above the age of 25 were admitted, due to the origin of EINP in a rehabilitation centre for children.

\section{Outcome measures}

\section{PALOC-s}

The PALOC-s was developed in 1998, based on the publications of the International Working Party on the Vegetative State (Andrews, 1996a, 1996b), and of the Aspen Neurobehavioural Conference (Giacino et al., 1997). In the PALOC-s, eight hierarchal levels were distinguished: (1) Coma, (2) VS hypo-responsive, (3) VS reflexive state, (4) VS high (re-)active, (5) MCS transitional state, (6) MCS inconsistent reactions, (7) MCS consistent reactions, and (8) Consciousness. Each level was illustrated with three to four short descriptive sentences. Because the level of 
arousal and awareness of unconscious patients can alter in a time span of minutes (Andrews, Murphy, Munday, \& Littlewood, 1996; Wilson, Powell, Brock, \& Twaithes, 1996), three states are discerned in scoring the PALOC-s: the "general state", the "best state", and the "worst state". The complete PALOC-s is presented in Appendix I.

\section{WNSSP}

The protocol from the Western Neuro Sensory Stimulation Profile (WNSSP) was used to examine patients (Ansell et al., 1989) in a systematic manner. The WNSSP was developed to assess slow-to-recover patients with severe brain injury, and can be used for clinical evaluation as well as for the study of recovery patterns. The WNSSP consists of 33 items, representing a broad range of behaviours: arousal and attention, expressive communication, and the responses to auditory, visual, tactile and olfactory stimulation. The WNSSP results in a total score varying between 0 and 113, indicating the level of alertness, the level of cognitive functioning, and the appropriateness of reactions to simple commands.

In a small pilot study conducted in 1996 with seven patients, it was found that this protocol has good qualities for repeated structured examinations of young unconscious patients' levels of function (Eilander, van Rijen, \& Verwijk, 1997). Therefore, despite a mild floor effect which was shown to be present in this instrument (O'Dell, Jasin, Lyons, Stivers, \& Meszaros, 1996b), it was decided to use the WNSSP-protocol for this study. Recently, Lavrijsen et al. (2003) proposed to use the WNSSP protocol in order to differentiate vegetative patients from patients in coma, in a locked-in state, or in a minimally conscious state.

\section{DRS}

The Disability Rating Scale (DRS) was used to establish a global level of disability. The DRS has been developed for quantitatively assessing the disability of patients with severe brain injury (Rappaport, Hall, Hopkins, Belleza, \& Cope, 1982), the outcome ranging from coma to independent participation in the community. The DRS consists of eight items and results in a score from 0 (no disability) to 29 (extremely vegetative). A score of 30 is used in outcome research when a patient has died. The DRS has been recommended as one of the most appropriate instruments in assessing the (long-term) outcome of severely brain injured patients (Bullock et al., 2002). The first three items of the DRS are very similar to the items in the GCS, assessing arousal, reactivity and responding. The next three items assess the level of cognitive independency during self-care activities. The last two items measure the level of community participation. 


\section{Patient assessment}

The patients in this study were examined once every two weeks from admission to discharge by the first author, who is a neuropsychologist with more than 20 years experience in the rehabilitation of brain-injured children and adolescents. The patients were seated in a wheelchair or in an upright position in bed in a small quiet room. The examination began with a three-minute period without any stimulation followed by the application of the WNSSP. After concluding the WNSSP, another three-minute silent period was established. The total procedure lasted between 15 and 30 minutes. Immediately after this examination the investigator calculated the WNSSP scores, administered the PALOC-s, and part of the DRS (items 1, 2, 3, 7, and 8). On the same day, the last part of the DRS was administered (items 4, 5, and 6) after consulting the nursing staff.

The total examination procedure was recorded with a Hi8 video camera. The camera was placed at a height of $2 \mathrm{~m}$ in front of the chair or bed. In most of the cases, the patients were captured fully on film. Sometimes the lower parts of their legs, and/or their feet were out of range of the camera. It was not possible to zoom in on the patient. Therefore, small movements of the eyes and face could not always be detected.

Some items of the WNSSP could not be administered in all cases. For instance, young children were not able to read simple commands and patients with no pupillary reflex could not be stimulated by shining a bright light into their eyes. In those cases, the items were skipped and the scoring was adapted, as explained in the section on statistical analysis.

\section{Validation procedure}

\section{Development and initial validation of the PALOC-s}

To examine the usefulness and reliability of the first draft of the PALOC-s, four observers were recruited: three physicians and one neuropsychology trainee, all with relevant experience in examining severely neurologically impaired patients. Participation of the observers was voluntary. They were trained by studying the relevant literature (Andrews, 1996a, 1996b; Giacino, 2002; Giacino et al., 2002a, 2002b) and by attending two training meetings with the first author. During the meetings the objectives and the design of the study were explained, the PALOC-s was discussed and five videotapes of the examination of patients were observed and discussed, resulting in scoring the PALOC-s. The videotapes used in this training procedure were excluded from the actual study. Of the remaining videotapes, one tape of each patient $(n=44)$ was selected. Half of the tapes were selected at random and half of them were chosen in such a way 
that in each category of the PALOC-s at least three tapes were present, according to the rating score of the examination by the first author. Each tape was copied on to a VHS-tape and randomly numbered to avoid any possibility of identification of the patient. In a period of two to three weeks, each observer rated 11 tapes in a unique, randomly determined sequence. After each period, the sets were exchanged, until all tapes had been observed by each of the four observers. In this way, the inter-observer reliability could be determined.

To determine the test-retest reliability, one observer (the neuropsychology trainee) rated the same 44 tapes again in a new random sequence, $4-6$ months later.

During a discussion round at the end of this procedure, the usefulness of the PALOC-s was discussed. The four observers proposed changing some unclear descriptions of the three minimally conscious levels and of the conscious level. These changes were discussed with the clinical treatment team of EINP, who had become very experienced using the PALOC-s. Finally, the proposed version was discussed in writing and via e-mail with the four observers. The first author then made the final decisions regarding the formulation of the PALOC-s items. The final version of the PALOC-s is presented in Appendix 1, while examples of the changes that were made with regard to the first version are presented in Appendix 2.

\section{Reliability of the final version of the PALOC-s}

To investigate the reliability of the final version of the PALOC-s, two more observers were recruited: a psychology trainee without clinical experience and a general practitioner who was a member of the clinical team in 2006. They were trained according to the above-described procedure, seeing the same five videotapes as the first four observers. Subsequently, and unaware of the ratings of the first four observers, they observed and rated the same 44 videotapes, each in a new random sequence.

\section{Responsiveness}

The responsiveness of a scale is the sensitivity of that scale to measure changes over time in the observed variable. To determine the responsiveness of the PALOC-s, the investigator's scores of the assessments during admission and discharge were compared.

\section{Validity}

To investigate the validity of the PALOC-s, 56 more videotapes were randomly selected out of the remaining 278 and, together with the original 
44 tapes, observed in a random sequence by the psychology trainee without clinical experience. This resulted in 100 ratings. Subsequently, these scores were correlated to the scores of the WNSSP and DRS to determine the concurrent validity. Some patients were represented two to four times in this total of 100 tapes. To analyse the effect of the multiple representations of the same patients on the validity scores, all ratings were divided into four subgroups, in such a way that each patient was represented only once in each subgroup. The first subgroup of scores consisted of the ratings of 44 patients based on the original tapes, the second subgroup consisted of ratings of 36 new tapes of these 44 patients, the third of 16 other tapes of the 44 patients, and the last subgroup of scores consisted of ratings of 4 more tapes of the 44 patients.

\section{Statistical analyses}

The raw scores of the WNSSP were firstly converted into percentages (WNSSP\%), based on the highest attainable score of all the items that were actually administered. This was done because in some cases not all items could be administered (see patient assessment).

The inter-observer reliability scores and the intra-observer test-retest scores were calculated using Spearman's rank-order correlation coefficient $\left(r_{s}\right)$. The inter-observer agreement scores and the test-retest agreement scores were calculated by using Cohen's weighted Kappa $\left(\kappa_{\mathrm{w}}\right)$.

Responsiveness is defined as the ability of the PALOC-s to detect changes in the clinical state of the patient during the course of admission to EINP, comparing the scores of the first and last examination by the first author. Responsiveness was investigated by calculating the standardised effect size according to Cohen, that is by dividing the mean difference between the first and last examination scores by the mean of the standard deviations of the first and last examination scores ( 0.2 is a small effect, 0.5 a moderate effect and 0.8 or higher represents a large effect). In addition, the paired $t$-test was used to investigate the significance of the changes.

To investigate the validity of the PALOC-s, Spearman's rank-order correlation coefficient $\left(r_{s}\right)$ was used, correlating the PALOC-s with the WNSSP\% and the DRS.

Spearman's rank-order correlation coefficient $\left(r_{s}\right)$, mean scores, standard deviations and the $t$-test score were calculated using SPSS version 11.0.1. Cohen's weighted Kappa $\left(6_{\mathrm{w}}\right)$ was calculated using MedCalc version 7.3.0.1.

To control for possible age effect on the scores, the total group was split into three age groups: $2-10$ years $(n=11), 11-20$ years $(n=22)$, and older than 20 years $(n=11)$. In each subgroup the above mentioned Spearman's rank-order correlation coefficients $\left(r_{s}\right)$ were calculated. 


\section{RESULTS}

\section{Patient characteristics}

A cohort of 44 consecutively admitted patients (aged 2-25 years, mean $=16.0$ years; $64 \%$ male; $73 \%$ traumatic brain injury) with severe brain injury (initial GCS at time of injury $\leq 8$ ) participated in this study. Admission to EINP took place between 23 and 198 days after injury (mean $=71, S D=25.5)$, between January 2001 and September 2003. All patients were in a vegetative state $(77 \%)$ or in a minimally conscious state (23\%) upon admission. This was determined by the clinical team, using the classification presented in 1996 by the International Working Party on the Management of the Vegetative State (Andrews, 1996a, 1996b), with one exception. In order to avoid uncertainty, the clinical team decided to classify the "transitional state" as MCS instead of an undecided category between VS and MCS.

As the length of stay varied between 26 and 197 days (mean $=111$, $S D=41.1$ ), and sometimes patients could not be examined because of their physical condition, the number of examinations per patient varied in accordance (range 2-14). This resulted in a total number of 327 videotaped examinations.

To demonstrate the clinical applicability of the PALOC-s, three cases out of the 44 are presented in Boxes 1, 2 and 3.

\section{Development and initial validation of the PALOC-s}

The multi-rater inter-observer reliability of the PALOC-s draft version is presented in Tables 1 and 2. The correlations varied between .85 and .94 (Table 1), and the kappa's varied between .85 and .95 (Table 2), while the standard error $(S E)$ was small in all cases.

TABLE 1

Correlations $\left(r_{s}\right)$ between the six pairs of observers on the draft version of the PALOC-s

\begin{tabular}{lccc}
\hline $\begin{array}{l}\text { Pairs of } \\
\text { observers }\end{array}$ & $r_{\mathrm{s}}$ general & $r_{\mathrm{s}}$ best & $r_{\mathrm{s}}$ worst \\
\hline $1 \times 2$ & $.94^{* *}$ & $.86^{* *}$ & $.92^{* *}$ \\
$1 \times 3$ & $.92^{* *}$ & $.90^{* *}$ & $.94^{* *}$ \\
$1 \times 4$ & $.85^{* *}$ & $.85^{* *}$ & $.89^{* *}$ \\
$2 \times 3$ & $.94^{* *}$ & $.92^{* *}$ & $.92^{* *}$ \\
$2 \times 4$ & $.92^{* *}$ & $.92^{* *}$ & $.94^{* *}$ \\
$3 \times 4$ & $.92^{* *}$ & $.88^{* *}$ & $.91^{* *}$ \\
\hline${ }^{* *} p<.01$ (2-tailed). & &
\end{tabular}


TABLE 2

Inter-observer agreement scores $\left(\kappa_{\mathrm{w}}\right)$ between the six pairs of observers on the draft version of the PALOC-s

\begin{tabular}{lcccccc}
\hline $\begin{array}{l}\text { Pairs of } \\
\text { observers }\end{array}$ & $\begin{array}{c}\kappa_{w} \\
\text { general }\end{array}$ & $\begin{array}{c}\text { SE } \kappa_{w} \\
\text { general }\end{array}$ & $\begin{array}{c}\kappa_{w} \\
\text { best }\end{array}$ & $\begin{array}{c}\text { SE } \kappa_{w} \\
\text { best }\end{array}$ & $\begin{array}{c}\kappa_{w} \\
\text { worst }\end{array}$ & $\begin{array}{c}\text { SE } \kappa_{w} \\
\text { worst }\end{array}$ \\
\hline $1 \times 2$ & .93 & .02 & .87 & 03 & .90 & .04 \\
$1 \times 3$ & .95 & .01 & .89 & .02 & .95 & .02 \\
$1 \times 4$ & .90 & .02 & .85 & .04 & .88 & .04 \\
$2 \times 3$ & .93 & .02 & .92 & .02 & .89 & .04 \\
$2 \times 4$ & .91 & .02 & .92 & .03 & .92 & .03 \\
$3 \times 4$ & .92 & .03 & .89 & .03 & .92 & .04 \\
\hline
\end{tabular}

The test-retest reliability correlation was .96 for the general state, .95 for the best state and .96 for the worst state. All these correlations were significant at the .01 alpha level.

The test-retest agreement kappa was .94 for the general state, .94 for the best state, and .95 for the worst state $(S E$ in all cases $=.02)$.

\section{Responsiveness}

The change score on the PALOC-s between the first and the last examination during admittance to EINP was positive (indicating improvement), with a $t$-test score for paired samples being $8.24(p<.01)$. The standardised effect size according to Cohen was 1.30, which can be considered as high.

\section{Reliability}

For the final version of the PALOC-s, the two-rater correlation score for the general state was .94 . The correlation for the best state was .88 and for the worst state .94 . All these correlations were significant at the .01 alpha level.

The two-rater agreement kappa score between the fifth and sixth observer was $.94(S E=.02)$. The kappa for the best state was .83 $(S E=.05)$ and for the worst state $.96(S E=.02)$.

\section{Validity}

The correlations of the PALOC-s score of the fifth observer with the WNSSP\% and the DRS are presented in Table 3. On all 100 observations, the correlations with the WNSSP\% varied between .93 and .91 and with the DRS the correlations varied between .85 and .86. All correlations were significant at the .01 alpha level.

In three of the four subgroups of observations, the correlations with the WNSSP\% scores varied between .89 and .92 , while the correlations with 
TABLE 3

Correlations $\left(r_{s}\right)$ of the score of the fifth observer on the PALOC-s with the WNSSP\% and the DRS, in all observations together, as well as in subgroups with independent observations

\begin{tabular}{lcccccc}
\hline & $\begin{array}{c}\text { WNSSP\% } \\
\text { General } \\
\text { state }\end{array}$ & $\begin{array}{c}\text { DRS } \times \\
\text { General } \\
\text { state }\end{array}$ & $\begin{array}{c}\text { WNSSP\% } \\
\text { Best } \\
\text { state }\end{array}$ & $\begin{array}{c}\text { DRS } \times \\
\text { Best } \\
\text { state }\end{array}$ & $\begin{array}{c}\text { WNSSP\% } \\
\text { Worst } \\
\text { state }\end{array}$ & $\begin{array}{c}\text { DRS } \times \\
\text { Worst } \\
\text { state }\end{array}$ \\
\hline $\begin{array}{c}\text { All ratings } \\
\quad(n \mathrm{R}=100)\end{array}$ & $.93^{* *}$ & $.85^{* *}$ & $.91^{* *}$ & $.86^{* *}$ & $.92^{* *}$ & $.85^{* *}$ \\
$1(n \mathrm{R}=44)$ & $.91^{* *}$ & $.88^{* *}$ & $.88^{* *}$ & $.86^{* *}$ & $.92^{* *}$ & $.86^{* *}$ \\
$2(n \mathrm{R}=36)$ & $.92^{* *}$ & $.80^{* *}$ & $.90^{* *}$ & $.84^{* *}$ & $.91^{* *}$ & $.81^{* *}$ \\
$3(n \mathrm{R}=16)$ & $.91^{* *}$ & $.76^{* *}$ & $.90^{* *}$ & $.81^{* *}$ & $.89^{* *}$ & $.75^{* *}$ \\
$4(n \mathrm{R}=4)$ & .26 & .82 & .90 & .71 & .26 & .81 \\
\hline
\end{tabular}

${ }^{* *} p<.01$ (2-tailed). $n \mathrm{R}=$ number of ratings.

the DRS varied between .75 and .86 . All these correlations were significant at the .01 alpha level.

In the fourth subgroup of observations the correlations showed considerable variance, without attaining significance. This subgroup, however, consisted of only four patients.

To control for any bias in the selection of all 100 observation tapes, an analysis was performed of the distribution of the scores on the general state of the PALOC-s by the fifth observer. Table 4 shows that in the first three subgroups of independent observations, the distributions were very similar. Data from the very small fourth subgroup are not presented.

To control for a possible age effect on the scores, an analysis was performed in three different age groups: $2-10$ years $(n=11), 11-20$ years $(n=22)$, and older than 20 years $(n=11)$. All correlations between the PALOC-s scores of the two observers, and between the PALOC-s scores of both observers with the WNSSP\% and the DRS respectively, varied between .80 and .95 . These correlations were again significant at the .01

TABLE 4

Distribution of the scores of the fifth observer on the general state of the PALOC-s in the first three subgroups with independent observations. In each subgroup each patient is represented only once

\begin{tabular}{lcccc}
\hline Groups & $\begin{array}{c}\text { Lowest } \\
\text { score }\end{array}$ & $\begin{array}{c}\text { Highest } \\
\text { score }\end{array}$ & Mean & SD \\
\hline $1(n \mathrm{R}=44)$ & 1 & 8 & 4.32 & 2.52 \\
$2(n \mathrm{R}=36)$ & 2 & 8 & 4.39 & 2.21 \\
$3(n \mathrm{R}=16)$ & 2 & 8 & 4.56 & 1.9 \\
\hline$n \mathrm{R}=$ number of ratings. & & &
\end{tabular}


alpha level. Therefore, no age effects on the reliability and validity scores presented in this study were found.

\section{Box 1: Clinical presentation and acute management}

Patient 1 is a boy, who was 17 years old at the time of his injury. He was injured after joyriding under the influence of alcohol and hitting a bridge. He was found unconscious at the scene of the accident, where his GCS score was E1M4V2. Initial CT brain scanning demonstrated hypoxia, punctual haemorrhages, diffuse axonal injury, and a contusion to the brain stem. Some large haemorrhages were shown in the left parietal, right frontal and temporal lobes. There was also a left parietal impression fracture. The bone fragments were removed surgically. There were fractures to the jaw, the right mastoid, a perforation to the left ear, and an epidural haematoma. Patient 1 spent 20 days in the intensive care unit. A small amount of progress was observed: He opened his eyes to stimulation now and then, however there were no verbal responses. His GCS score progressed to E3M4V1. He was ultimately transferred to EINP 39 days after his injury.

\section{Rehabilitation programme and progress}

At admission patient 1 was in a vegetative state (PALOC-s level 2) and showed little muscle tension. He was undernourished, showing only substantial reactions to pain during passive movement of his shoulders. When his level of consciousness gradually improved, he appeared to become fatigued very quickly, demonstrating this as a staring gaze. He was not able to fixate on pictures or objects. Within weeks he was able to make eye contact for a couple of seconds. His motor responses improved. His facial mimic developed more and more, and sometimes he made sounds. He gradually started to smile and to look angry at people (PALOC-s level 5). He was capable of showing whether he liked something or not. There were periods in which he shut his eyes to isolate himself from his surroundings.

During the following recovery process, patient 1 showed resistance to the presented activities. He looked very angry; making threatening gestures, pushing away material, and isolating himself by putting his hands in front of his face. His mimic and behaviour could vary within situations. It was not clear whether these changes expressed his real emotional intentions. Patient 1 slowly became more co-operative and more directed towards tasks (PALOC-s 6). However, his attitude shifted and he became more and more resistant towards any activity. Patient 1 appeared depressed, therefore medication was administered. His mood 
improved within several days, however, there was still a tendency to act clownish, which made him difficult to handle.

At 195 days after admission to EINP, patient 1 was discharged to a regular rehabilitation facility. The PALOC-s score at discharge was 7 and the DRS-score was 9; 3.4 years after discharge, the DRS-score was 7.

To further analyse the relationship between the PALOC-s and the WNSSP\%, and between the PALOC-s and the DRS, a curve estimation procedure was performed. A straight line was the most appropriate fit for these relationships ( $\mathrm{Rsq}=.89$, respectively $\mathrm{Rsq}=.72$ ). Higher order curves did not explain a significantly larger proportion of variance. In Figure 1, the linear regression lines show the relationships between the WNSSP\% and the DRS with the scores of the fifth observer on the general state of the PALOC-s. In Figure 2, the scores of patient 1 on the PALOC-s, the WNSSP and the DRS of each measurement are graphically presented.

\section{DISCUSSION}

In this study, the quality of the PALOC-s was investigated in a cohort of young persons with severe brain injury. The reliability (inter-rater and testretest), the responsiveness, and the concurrent validity were all shown to be good.
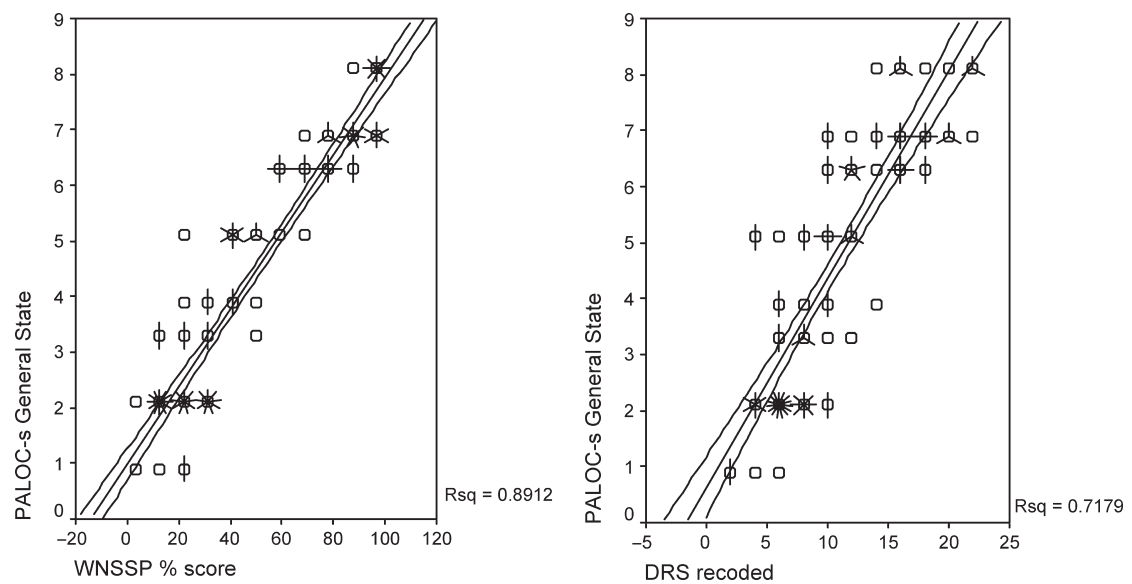

Figure 1. Individual data points and linear regression lines (including 95\% CI lines) showing the relation of the WNSSP\% and the DRS to the general state score of the fifth observer on the PALOC-s (for comparability of the graphics the DRS-scores were recoded: A score of 1 was recoded into 29 , a score of 2 into 28 , etc., always summing up to 30 ). 

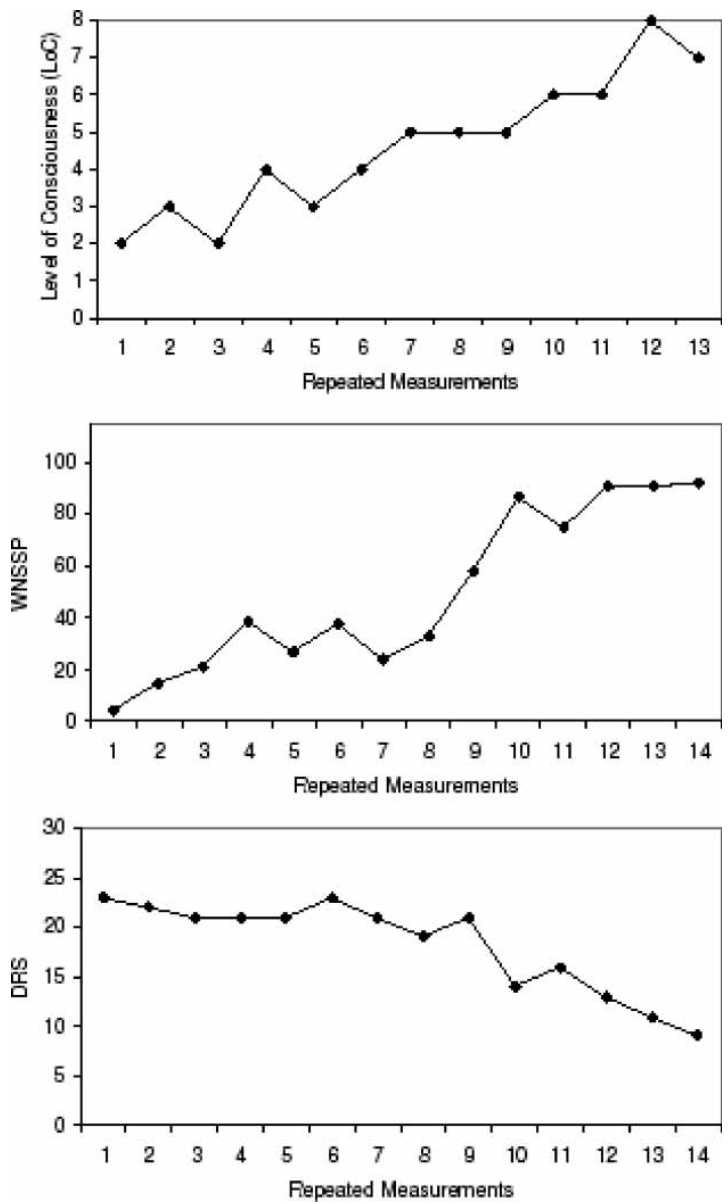

Figure 2. Graphic presentations of the PALOC-s, WNSSP and DRS scores.

As far as we know, this is the first observation scale that distinguishes among a wide range of disturbed consciousness levels, and that is based on some theoretical considerations about the concept (Andrews, 1996b; Freeman, 1997; Giacino, 1997; Giacino \& Kalmar, 1997; Giacino et al., 1997; Jennett, 2002). Insight is increasing concerning the gradual improvement of consciousness during recovery from coma after severe brain injury (O'Callaghan et al., 2004). A reliable and valid assessment of such a process is therefore of great importance for the clinical management of these patients (Laureys, Owen, \& Schiff, 2004). 
Box 2: Clinical presentation and acute management

Patient 2 is a man who was 25 years of age at the time of injury. He was injured in a traffic accident, after being hit by a train. He was immediately unconscious. The initial GCS-score is unknown.

Initial computed tomography (CT) brain scanning demonstrated a subdural haematoma in the left parietal and right frontal lobes. There were also skull fractures. Initial neurosurgical treatment consisted of the application of an intracranial pressure gauge, and a bilateral craniotomy. The haematoma was removed. In addition, an amputation of the lower limb had to be performed. Patient 2 spent 16 days in the ICU. His GCS score progressed to E2M5V1 while reacting to some stimulation.

\section{Rehabilitation programme and progress}

At admission patient 2 was in a vegetative state (PALOC-s level 3). He showed very little progress. Sometimes there were responses to pain, temperature and touch. He responded by closing his eyes and making chewing movements. He often showed a distracting, gazing expression. Sometimes there was tracking of the eyes towards objects (PALOC-s level 4). He did not show any anticipating behaviour. No progress was seen, and he was sometimes difficult to arouse.

Two months after admission to EINP he suffered a large epileptic seizure. From then on, he did not show any reaction to stimulation. He was discharged to a nursing home 111 days after admission to EINP. The PALOC-s level at discharge was 2. Patient 2 deceased 6 months later. In Figure 3, the scores of patient 2 on the PALOC-s, the WNSSP and the DRS of each measurement are graphically presented.

\section{Assessing levels of consciousness}

The distinction between the VS and the MCS in literature is clear and increasingly undisputed (Jennett, 2002), despite some opposing reactions (Bernat, 2002; Coleman, 2002; Shewmon, 2002) to one of the publications advocating this distinction (Giacino et al., 2002b). One can dispute at which level the distinction has to been made between VS and MCS. The International Working Party could not reach agreement as to whether the transitional state (PALOC-s level 5) was vegetative or non-vegetative (Andrews, 1996b). According to the criteria of Giacino et al (2002a), level 5 of the PALOC-s is not a minimally conscious level, because its description lacks any simple command following, gestural or verbal responses, intelligible 

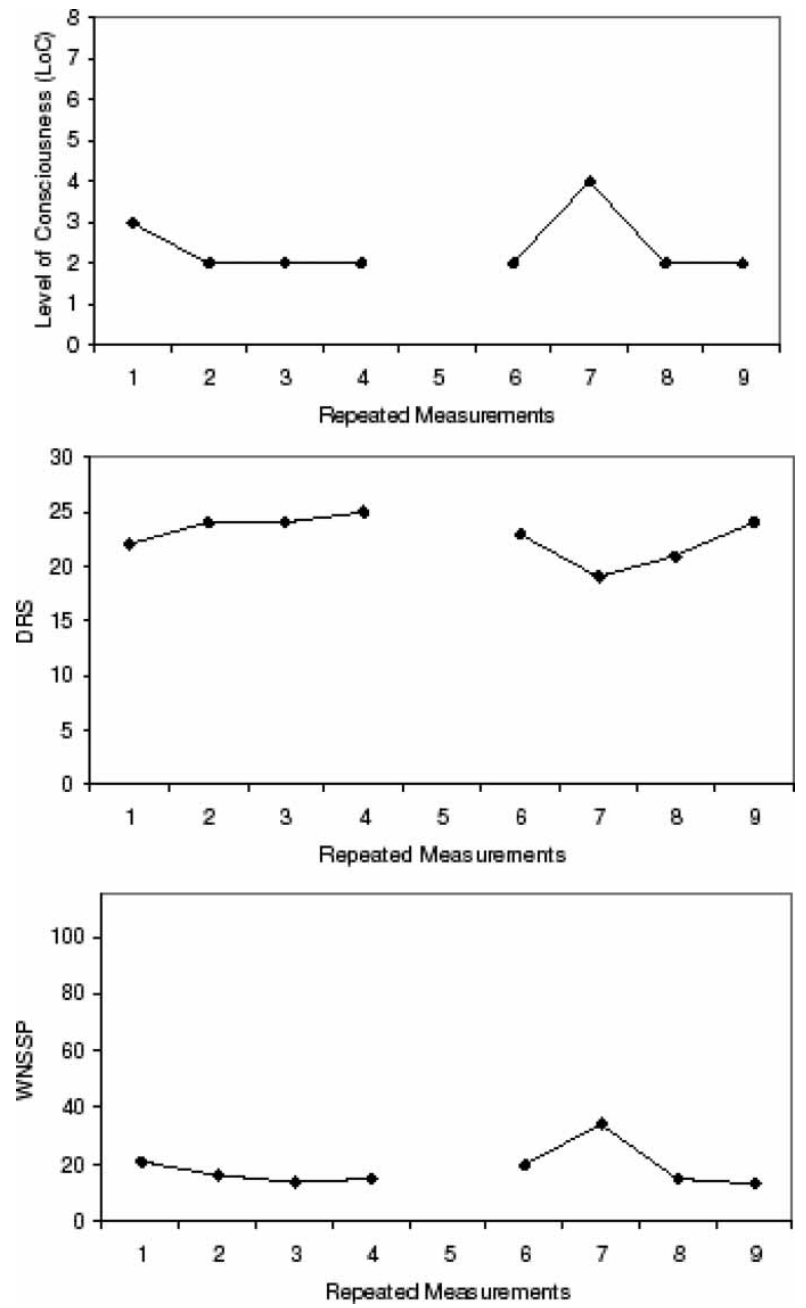

Figure 3. Graphic presentations of the PALOC-s, WNSSP and DRS scores.

verbalisation or purposeful behaviour. But, as was recently stated by the Royal College of Physicians (2003), the main features of PALOC-s level 5, such as a smile in response to a relative, an attempt to reach out for an object (albeit in an automatic way, and not in reaction to a question) and fixating people systematically, are all incompatible with the vegetative state. Nevertheless, these behavioural features are not sufficient for classification of patients as minimally conscious. Therefore, the precise distinction 
between VS and MCS can still be argued. Recently, Lavrijsen identified eight patients in Dutch nursing homes without the ability to follow simple commands and who met the criteria of the transitional state as described by the International Working Party (Andrews, 1996a; Lavrijsen, van den Bosch, Koopmans, \& van Weel, 2005). Lavrijsen recommended classification of these patients as not being in a vegetative state and stressed the need for further research because of the medical-ethical implications. Relating the PALOC-s in different phases of recovery to long-term outcome levels, combined with modern imaging techniques, could perhaps shed more light on the question concerning which level marks the distinction between the vegetative and minimally conscious state, assuming these levels are genuine.

The question whether it is possible and necessary to identify gradations within the supposed VS and the MCS, can be answered positively. At the introduction of the MCS, the Aspen Workgroup on the Vegetative and Minimally Conscious States concluded that there were no compelling arguments to divide the MCS into further gradations (Giacino et al., 1997). The results of the present study show, however, that in the MCS there are differences in the way patients react to stimuli as given in the WNSSP protocol. The individual data points in Figure 1, showing the relation between the PALOC-s and the WNSSP, demonstrate a clear distinction between the three levels of the MCS. This is important for both clinical management and outcome research.

In the VS, the distinction between levels 2 and 3 is not as clear and is therefore disputable. Level 4, however, can clearly be distinguished based on the relationship with the WNSSP scores. In 1980, Plum and Posner already stated that some vegetative patients are akinetic and mute, while others may be restless, noisy and hypermobile (Plum \& Posner, 1980, p.6). This is presumably related to parts of the brain which may have recovered either partially or fully, which can be a sign that (some) recovery is possible (Minderhoud, 2003). Location and extent of the damage, especially of diffuse axonal injury and/or of thalamic damage, may be responsible for these differences (Jennett, Adams, Murray, \& Graham, 2001; Povlishock \& Katz, 2005). The less axonal damage the more recovery may occur. Therefore, the distinction between levels 3 and 4 of the PALOC-s might be crucial for prognostic reasons. Also, one can argue whether or not level 7 belongs to the MCS. As Giacino stated, the boundary between the MCS and consciousness is questionable and unclear (Giacino et al., 1997). It can be presumed that (some of the) patients at level 7 of the PALOC-s were fully conscious but had severe cognitive and behavioural deficits. For clinical reasons, the importance of the distinction between levels 7 and 8 is the (in)ability of the patient to communicate comprehensibly (Jennett, 2002). 


\section{BOX 3: Clinical presentation and acute management}

Patient 3 was a boy of 6 years old at the time of injury. He nearly drowned in a small lake during an outing with his family. He was pulled out of the water after at least 15 minutes. He was immediately resuscitated by paramedics for about 9 minutes. At admission to the hospital, the GCS score was E1M3Vt. He suffered hypothermia $\left(32^{\circ} \mathrm{C}\right)$, and after warming up he developed a fever. Initial CT brain and magnetic resonance imaging (MRI) scanning demonstrated diffuse hypoxia and anoxia, and a diffuse white matter lesion. Patient 3 spent 8 days at the ICU. He was transferred to EINP 56 days after injury.

\section{Rehabilitation programme and progress}

Patient 3 was in a vegetative state on admission to EINP (PALOC-s level 3), sometimes showing spontaneous motor activity. Initially it was unclear if there were auditory problems. He generally did not respond to auditory stimulation, although he showed some signs of recovery of consciousness.

Gradually, patient 3 made progress. His level of consciousness improved and after two months, he was able to handle some simple therapeutic exercises (PALOC-s level 6). However, his behaviour appeared to be automatically triggered. He was especially focused on people and moving objects. Sporadically he spoke a few words. He often smiled when others talked to him. He was easily distracted, and showed some functional problems.

Although his level of consciousness progressed, patient 3 showed a disturbed pattern of information processing. In addition, he suffered from dyspraxia.

$\mathrm{He}$ was discharged to a regular rehabilitation facility at 83 days after admission to EINP. The PALOC-s level at discharge was 6 and the DRS-score was 19. Seven months after discharge, the DRS-score was 11. In Figure 4, the scores of patient 3 on the PALOC-s, the WNSSP and the DRS of each measurement are graphically presented.

A persisting question is whether a new scale is actually necessary. An affirmative answer has been given in the recent past by the National Health and Medical Research Council of the Australian Government, stating the need for refinement of technologies to identify subclasses of unconscious patients (O'Callaghan et al., 2004). The following scales and methods were developed to investigate patients with disturbed consciousness: the Coma/Near Coma Scale (CNC; Rappaport et al., 1992), the Coma Recovery Scale (CRS; O’Dell, Jasin, Lyons, Schmidt, \& Moore, 1996a), the Coma Recovery Scale-Revised (CRS-r; Giacino, Kalmar, \& Whyte, 2004), the Rancho 

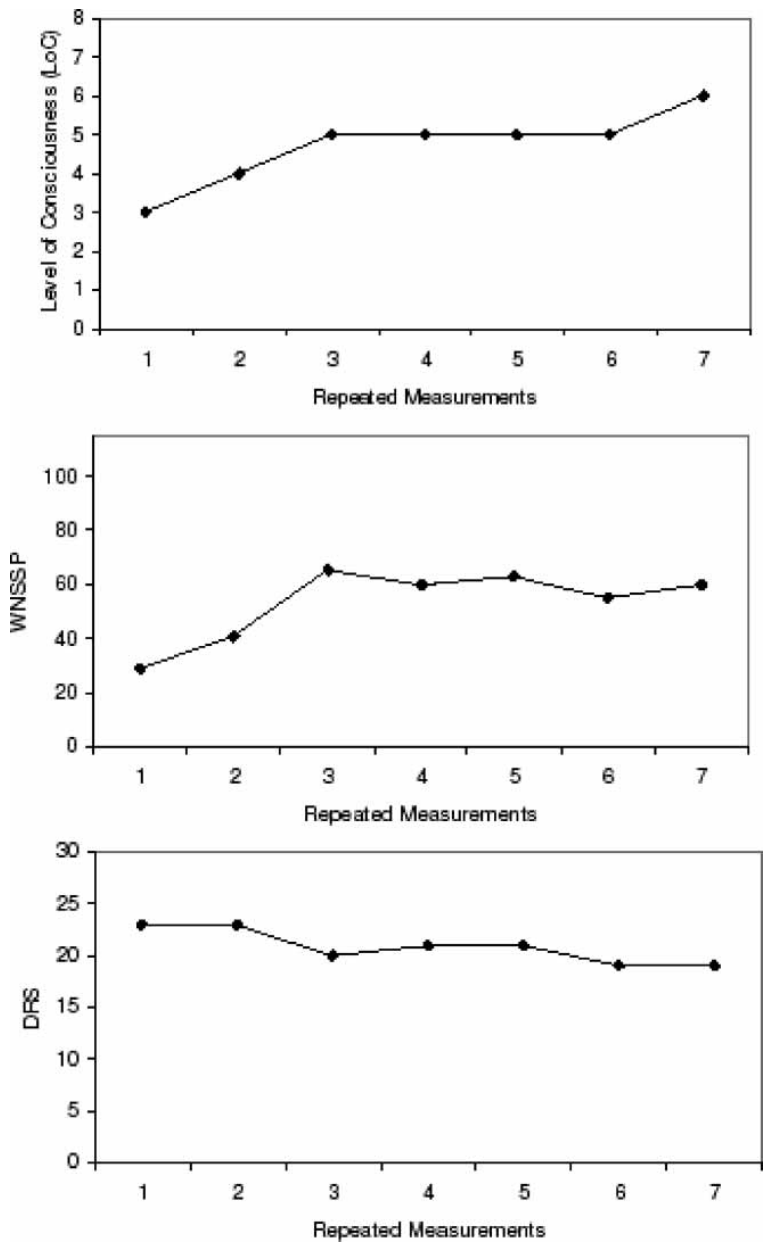

Figure 4. Graphic presentations of the PALOC-s, WNSSP and DRS scores.

Levels of Cognitive Functioning Scale (RLCFS; Hagen, 1998; Hagen et al., 1972), the Sensory Stimulation Assessment Measure (SSAM; Rader \& Ellis, 1994), the Sensory Modality Assessment and Rehabilitation Technique (SMART; Gill-Thwaites, 1997; Gill-Thwaites \& Munday, 2004; Wilson \& Gill-Thwaites, 2000) and the Western Neuro Sensory Stimulation Profile (WNSSP; Ansell et al., 1989). The Disorders of Consciousness Scale (DOCS) was presented recently with this same purpose (Pape, Heinemann, Kelly, Hurder, \& Lundgren, 2005). The most important difference between the PALOC-s and the scales mentioned above, is the possibility of the usefulness of the PALOC-s in differentiating between distinct levels of 
consciousness from coma to full consciousness. All others scales either add up to a total score (as in the WNSSP and the CRS-r), or the results are partly qualitatively presented (as in the SSAM and the SMART), or the used terms and descriptions are no longer valid for the VS and the MCS (as in the CNC). A disadvantage of the SMART is that a special kit must be purchased, combined with a training programme given by the developers of the SMART. The RLCFS was developed before the concepts of the vegetative or minimally conscious states were presented and results in a combination of levels of consciousness (Levels I to IV) and cognitive functioning (Levels IV to X), without a clear connection to the VS and MCS (Hagen, 1998). Furthermore, the RLCFS offers little sensitivity in discriminating subtle changes in the state of consciousness (Bekinschtein et al., 2005).

The second characteristic of the PALOC-s, which is not present in any of the other scales, is the possibility of scoring fluctuations of consciousness during the examination by means of the best score and worst score. As has been demonstrated in our data, these scores were valid and highly reliable. In this study, the PALOC-s was scored after having administered the WNSSP first. An important question is whether the scale can be scored without a thorough examination. We did not investigate this, however we gathered the PALOC-s scores of the clinical team which were given in the same weeks as the examinations for this study were executed. All correlations between the PALOC-s scores of the clinical team and the scores of the investigator of the first 10 assessments were high and significant at the .01 alpha level. Although the draft version of the PALOC-s was used instead of the final slightly modified version, it can be assumed that experienced clinicians are able to score the PALOC-s reliably, without first administering the WNSSP.

\section{Limitations}

The method used here to investigate the reliability of the PALOC-s is generally applied in other studies for these kinds of scales (Alderson \& Novack, 2003; Gwet, 2001; Wilson et al., 2002). We decided, however, to adapt the initial descriptions of some levels based on the experiences of the four observers. Subsequently, it was necessary to extend the study with two more observers to establish the reliability and validity for the definitive form of the PALOC-s. Two observers are generally not sufficient in investigating the reliability of such a scale. However, the changes made to the draft version of the PALOC-s were minor, which leads us to conclude that reliability scores of the draft were indicative of the reliability of the final version. This is further demonstrated by the strong correlation between the scores of the first four observers and the scores of the fifth and sixth observers on the general state of the PALOC-s. 
To investigate the validity of a new observation scale, the construct validity should be considered first (Neale \& Liebert, 1986). One of the possibilities is to relate the observed level of consciousness to neurophysiological parameters which are supposed to reflect the level of activity of the brain. For instance, electrodermal activity (EDA) (Boucsein, 1993), evoked or eventrelated potentials (EP) (Davidson, Jackson, \& Larson, 2000; Guérit, de Tourtchaninoff, Soveges, \& Mahieu, 1993), positron emission tomography (PET) scan or functional magnetic resonance imaging (fMRI) (Laureys et al., 2004) could be used. In a clinical situation with brain injured patients, however, either the technique is too difficult to execute (as is the case with fMRI) or it cannot be conducted because it requires some patient co-operation (as is the case with all techniques). For this reason, in order to investigate the validity, we compared other observational scales, which are supposed to give insight into the level of consciousness, with our new scale.

Another problem in this validation study was the small number of subjects. The only possible way to accomplish a desirable subject group larger than the available 44 patients was to include multiple observations of the same patient. This method of investigating the validity of a scale is somewhat unusual but not unique (Gill-Thwaites, 1997; Moseley \& Yap, 2003; Starmark, Stålhammer, Holmgren, \& Rosander, 1988). The procedure resulted, respectively, in high correlations between the PALOC-s with the WNSSP and DRS scores. The correlations in the independent subgroups of patients were high as well. This being true for all subgroups except the smallest one. After taking a closer look, the raw data showed that this was due to the scores of only one patient. Therefore, the information from this subgroup does not threaten the general conclusion being that the validity of the PALOC-s is high.

Finally, due to the nature of admission criteria to EINP, this study was executed with a cohort of patients up to 25 years of age. Although it can be assumed there will be little difference in the way unconscious adults above the age of 25 react compared to young adults, further research is necessary to confirm this.

\section{Future research}

The relationships between the levels of the PALOC-s and neuropathological and neurophysiological variables should be investigated in future research to obtain more clarity concerning the significance of the different levels. In addition, it is important to investigate the predictive power of the PALOC-s, especially for the best and worst scores.

Finally, confirmation is needed about the assumption that the PALOC-s is also reliable and valid for adult patients. It is therefore important to repeat this study with patients older than 25 years. 


\section{GENERAL CONCLUSION}

The development of a level-of-consciousness scale for patients with a disturbed level of consciousness is a difficult task. Generally, only small numbers of patients can be included, sufficiently experienced independent observers are scarce, and a gold standard with which to compare the new data does not exist. In this study, to our knowledge, the best possible solutions for these problems were chosen. This resulted in the presentation of a reliable and valid scale, the PALOC-s, to determine the level of consciousness in (young) patients with disturbed consciousness after severe brain injury. The PALOC-s should be scored after a structured assessment by experienced and trained staff members.

Until further research can confirm or deny these findings, the PALOC-s offers the opportunity for clinical teams in hospitals and rehabilitation centres to evaluate the course of recovery for patients with a disturbed level of consciousness in the post-acute phase.

\section{REFERENCES}

Alderson, A. L., \& Novack, T. (2003). Reliable serial measurement of cognitive processes in rehabilitation: The cognitive log. Archives of Physical Medicine and Rehabilitation, 84, $668-672$.

American Congress of Rehabilitation Medicine (1995). Recommendations for use of uniform nomenclature pertinent to patients with severe alterations in consciousness. Archives of Physical Medicine and Rehabilitation, 76, 205-209.

Andrews, K. (1996a). International working party on the management of the vegetative state. Brain Injury, 10(11), 797-806.

Andrews, K. (1996b). International working party, report on the vegetative state. London: The Royal Hospital for Neuro-disability. From http://comarecovery.org/pvs.htm

Andrews, K., Murphy, L., Munday, R., \& Littlewood, C. (1996). Misdiagnosis of the vegetative state: Retrospective study in a rehabilitation unit. British Medical Journal, 313, $13-16$.

Ansell, B. J., Keenan, J. E., \& de la Rocha, O. (1989). Western Neuro Sensory Stimulation Profile: A tool for assessing slow-to-recover head-injured patients (Handbook). Tustin, CA: Western Neuro Care Centre.

Bekinschtein, T., Tiberti, C., Niklison, J., Tamashiro, M. R. M., Carpintiero, S., et al. (2005). Assessing level of consciousness and cognitive changes from vegetative state to full recovery. Neuropsychological Rehabilitation, 15(3-4), 307-322.

Bernat, J. L. (2002). Questions remaining about the minimally conscious state. Neurology, 58, $337-338$.

Borer-Alafi, N., Gil, M., Sazbon, L., \& Korn, C. (2002). Loewenstein communication scale for the minimally responsive patient. Brain Injury, 16(7), 593-609.

Boucsein, W. (1993). Methodological issues in electrodermal measurement. In J. C. Roy, W. Boucsein, D. C. Fowles \& J. H. Gruzelier (Eds.), Progress in electrodermal research (pp. 31-41). New York: Plenum Press.

Bullock, R. M., Merchant, R. E., Choi, S. C., Gilman, C. B., Kreutzer, J. S., Marmarou, A., et al. (2002). Outcome measures for clinical trials in neurotrauma. Neurosurgical Focus, 13(1), 1-11. 
Campbell, A. G. M. (1984). Children in a persistent vegetative state. British Medical Journal, $289,1022-1023$.

Coleman, D. (2002). The minimally conscious state. Definition and diagnostic criteria. Neurology, 58, 506.

Davidson, R. J., Jackson, D. C., \& Larson, C. L. (2000). Human electroencephalography. In J. T. Cacioppo, L. G. Tassinary \& G. G. Berntson (Eds.), Handbook of psychophysiology (pp. 27-52). Cambridge: Cambridge University Press.

Eilander, H. J., van Rijen, H. L. M., \& Verwijk, E. (1997). Behandeling van jonge mensen in een vegetatieve of laag bewuste toestand en van hun ouders. Tilburg: Rehab. Center Leijpark.

Eilander, H. J., Wijnen, V. J. M., Scheirs, J. G. M., de Kort, P. L. M., \& Prevo, A. J. H. (2005). Children and young adults in a prolonged unconscious state due to severe brain injury: Outcome after an early intensive neurorehabilitation programme. Brain Injury, 19(6), 425-436.

Freeman, E. A. (1996). The Coma Exit Chart: Assessing the patient in prolonged coma and the vegetative state. Brain Injury, 10(8), 615-624.

Freeman, E. A. (1997). Protocols for the vegetative state. Brain Injury, 11(11), 837-849.

Gezondheidsraad (1994). Patiënten in een vegetatieve toestand. Den Haag: Gezondheidsraad.

Giacino, J. T. (1997). Disorders of consciousness: Differential diagnosis and neuropathologic features. Seminars in neurology, 17(2), 105-111.

Giacino, J. T. (2002). The minimally conscious state. Definition and diagnostic criteria. Neurology, 58, 506-507.

Giacino, J. T., Ashwal, S., Childs, N., Cranford, R., Jennett, B., Katz, D. I., et al. (2002a). The minimally conscious state. Definition and diagnostic criteria. Neurology, 58, 349-353.

Giacino, J. T., Ashwal, S. C., Childs, N., Cranford, R., Jennett, B., Katz, D., et al. (2002b). The minimally conscious state: Definition and diagnostic criteria. Neurology, 59(9), 1473-1474.

Giacino, J. T., \& Kalmar, K. (1997). The vegetative and minimally conscious states: A comparison of clinical features and functional outcome. Journal of Head Trauma Rehabilitation, 12(4), 36-51.

Giacino, J. T., \& Kalmar, K. (2005). Diagnostic and prognostic guidelines for the vegetative and minimally conscious states. Neuropsychological Rehabilitation, 15(3-4), 166-174.

Giacino, J. T., Kalmar, K., \& Whyte, J. (2004). The JFK Coma Recovery Scale -Revised: Measurement characteristics and diagnostic utility. Archives of Physical Medicine and Rehabilitation, 85(12), 2020-2029.

Giacino, J. T., Kezmarsky, M. A., Deluca, J., \& Cicerone, K. D. (1991). Monitoring rate of recovery to predict outcome in minimally responsive patients. Archives of Physical Medicine and Rehabilitation, 72, 897-901.

Giacino, J. T., \& Zasler, N. D. (1995). Outcome after severe traumatic brain injury: Coma, the vegetative state, and the minimally responsive state. Journal of Head Trauma Rehabilitation, 10(1), 40-56.

Giacino, J. T., Zasler, N. D., Katz, D. I., Kelly, J. P., Rosenberg, J. H., \& Filley, C. M. (1997). Development of practice guidelines for assessment and management of the vegetative and minimally conscious states. Journal of Head Trauma Rehabilitation, 12(4), 79-89.

Gill-Thwaites, H. (1997). The Sensory Modality Assessment Rehabilitation Technique: A tool for assessment and treatment of patients with severe brain injury in a vegetative state. Brain Injury, 11(10), 723-734.

Gill-Thwaites, H., \& Munday, R. (2004). The Sensory Modality Assessment and Rehabilitation Technique (SMART): A valid and reliable assessment for vegetative state and minimally conscious state patients. Brain Injury, 18(12), 1255-1269.

Guérit, J. M., Tourtchaninoff, M., de, Soveges, L., \& Mahieu, P. (1993). The prognostic value of three-modality evoked potentials (TMEPs) in anoxic and traumatic comas. Neurophysiologie Clinique, 23, 209-226. 
Gwet, K. (2001). Handbook of inter-rater reliability. How to estimate the level of agreement between two or multiple raters. Gaithersburg: Stataxis Publishing Company.

Hagen, C. (1998). The Rancho Levels of Cognitive Functioning. Downey, CA: Rancho Los Amigos Medical Center.

Hagen, C., Malkmus, D., \& Durham, P. (1972). Levels of cognitive functioning. Downey, CA: Rancho Los Amigos Hospital.

Jennett, B. (2002). The vegetative state: Medical facts, ethical and legal dilemmas. Cambridge: Cambridge University Press.

Jennett, B., Adams, J. H., Murray, L. S., \& Graham, D. I. (2001). Neuropathology in vegetative and severely disabled patients after head injury. Neurology, 56, 486-490.

Jennett, B., \& Bond, M. (1975). Assessment of outcome after severe brain damage. The Lancet, $i, 480-483$.

Jennett, B., \& Plum, F. (1972). Persistent vegetative state after brain damage. A syndrome in search of a name. The Lancet, 1, 734-737.

Laureys, S., Owen, A. M., \& Schiff, N. D. (2004). Brain function in coma, vegetative state, and related disorders. The Lancet Neurology, 3(9), 537-546.

Lavrijsen, J. C. M., van den Bosch, J. S. G., Costongs, L. G. P., Eilander, H. J., Hoenderdaal, P. L., \& Minderhoud, J. M. (2003). Diagnostiek van vegetatieve toestand als basis voor medisch handelen op de grens van leven en dood. Nederlands Tijdschrift voor Geneeskunde, 147(5), $195-198$.

Lavrijsen, J. C. M., van den Bosch, J. S. G., Koopmans, R. T. C. M., \& van Weel, C., (2005). Prevalence and characteristics of patients in a vegetative state in Dutch nursing homes. Journal of Neurology, Neurosurgery, and Psychiatry, 76(10), 1420-1424.

Minderhoud, J. M. (2003). Traumatische hersenletsels. Houten/Mechelen: Bohn Stafleu Van Loghum.

Moseley, A. M., \& Yap, M. C. (2003). Interrater reliability of the TEMPA for the measurement of upper limb function in adults with traumatic brain injury. Journal of Head Trauma Rehabilitation, 18(6), 526-531.

Neale, J. M., \& Liebert, R. M. (1986). Science and behavior. An introduction to methods and research (3rd ed.). Englewood Cliffs, NJ: Prentice-Hall.

Ng, Y. S., \& Chua, K. S. (2005). States of severely altered consciousness: Clinical characteristics, medical complications and functional outcome after rehabilitation. NeuroRehabilitation, 20(2), 97-105.

O'Callaghan, M., Ahmed, S., Baumgarten, M., Green, A., Greenberg, P. B., Joseph, P., et al. (2004). Post-coma unresponsiveness (vegetative state): A clinical framework for diagnosis. An information paper. Australian Goverment/National Health and Medical Research Council.

O’Dell, M., Jasin, P., Lyons, N., Schmidt, S., \& Moore, D. E. (1996a). Interrater reliability of the Coma Recovery Scale. Journal of Head Trauma Rehabilitation, 11(3), 61-66.

O’Dell, M. W., Jasin, P., Lyons, N., Stivers, M., \& Meszaros, F. (1996b). Standardized assessment instruments for minimally-responsive, brain-injured patients. NeuroRehabilitation, 6 , 45-55.

Pape, T. L., Heinemann, A. W., Kelly, J. P., Hurder, A. G., \& Lundgren, S. (2005). A measure of neurobehavioral functioning after coma. Part I: Theory, reliability, and validity of Disorders of Consciousness Scale. Journal of Rehabilitation Research and Development, 42(1), 1-18.

Plum, F., \& Posner, J. B. (1980). The diagnosis of stupor and coma (3rd ed.). Philadelphia: F.A. Davis.

Povlishock, J. T., \& Katz, D. I. (2005). Update of neuropathology and neurological recovery after traumatic brain injury. Journal of Head Trauma Rehabilitation, 20(1), 76-94.

Rader, M. A., \& Ellis, D. W. (1994). The Sensory Stimulation Assessment Measure (SSAM): A tool for early evaluation of severely brain-injured patients. Brain Injury, 8(4), 309-321. 
Rappaport, M., Dougherty, A. M., \& Kelting, D. L. (1992). Evaluation of coma and vegetative states. Archives of Physical Medicine and Rehabilitation, 73, 628-634.

Rappaport, M., Hall, K. M., Hopkins, K., Belleza, T., \& Cope, D. N. (1982). Disability Rating Scale for severe head trauma: Coma to community. Archives of Physical Medicine and Rehabilitation, 63, 118-123.

Royal College of Physicians (2003). The vegetative state: Guidance on diagnosis and management. London: Royal College of Physicians.

Shewmon, D. A. (2000). Coma prognosis in children. Part I: Definitional and methodological challenges. Journal of Clinical Neurophysiology, 17(5), 457-466.

Shewmon, D. A. (2002). The minimally conscious state: Definition and diagnostic criteria. $\mathrm{Neu}-$ rology, 58, 506.

Shiel, A., Horn, S. A., Wilson, B. A., Watson, M. J., Campbell, M. J., \& McLellan, D. L. (2000). The Wessex Head Injury Matrix (WHIM) main scale: A preliminary report on a scale to assess and monitor patient recovery after severe head injury. Clinical Rehabilitation, 14, 408-416.

Starmark, J., Stålhammer, D., Holmgren, E., \& Rosander, B. (1988). A comparison of the Glasgow Coma Scale and the Reaction Level Scale (RLS85). Journal of Neurosurgery, 69, 699-706.

Teasdale, G., \& Jennett, B. (1974). Assessment of coma and impaired consciousness. A practical scale. Lancet, 2, 81-84.

Whyte, J., \& Glenn, M. B. (1986). The care and rehabilitation of the patient in a persistent vegetative state. Journal of Head Trauma Rehabilitation, 1(1), 39-53.

Wilson, J. T. L., Hareendran, A., Grant, M., Baird, T., Schulz, U. G. R., Muir, K. W., et al. (2002). Improving the assessment of outcomes in stroke. Use of a structured interview to assign grades on the modified Rankin scale. Stroke, 33, 2243-2246.

Wilson, S. L., \& Gill-Thwaites, H. (2000). Early indication of emergence from vegetative state derived from assessments with the SMART - A preliminary report. Brain Injury, 14(4), $319-331$.

Wilson, S. L., Powell, G. E., Brock, D., \& Thwaites, H. (1996). Behavioural differences between patients who emerged from vegetative state and those who did not. Brain Injury, 10(7), 509-516.

Manuscript received December 2006 Revised manuscript received September 2007

First published online March 2008

\section{APPENDIX 1}

\section{PALOC-S (POST-ACUTE LEVEL OF CONSCIOUSNESS SCALE)}

The classification presented below offers the possibility to discriminate between 8 levels of (un)conciousness in patients with severely disturbed consciousness, caused by acquired brain injury.

The PALOC-s is effective in evaluating possible changes in the level of consciousness in the post-acute phase (after the ICU-period), usually in days to weeks after the injury. 
Administration of the PALOC-s is only possible in combination with a structured examination of the patient, for instance with the Western Neuro Sensory Stimulation Profile (WNSSP; Ansell et al., 1989).

The examiner should be trained and have ample knowledge and experience with severely brain-injured patients.

Scoring is completed by encircling the number that coincides with the level of consciousness, giving the most accurate reading corresponding to the patient's behaviour, as described below.

a. What is the general level of consciousness the patient showed during the examination?

$\begin{array}{llllllll}1 & 2 & 3 & 4 & 5 & 6 & 7 & 8\end{array}$

Were there any moments during the investigation when the patient showed another level of consciousness?

b. Best level:

$\begin{array}{llllllll}1 & 2 & 3 & 4 & 5 & 6 & 7 & 8\end{array}$

c. Worst level:
$\begin{array}{llllllll}1 & 2 & 3 & 4 & 5 & 6 & 7 & 8\end{array}$

\begin{tabular}{|c|c|c|}
\hline Level & Score & Description of the levels \\
\hline \multirow[t]{2}{*}{ Coma } & \multicolumn{2}{|r|}{ Eyes are closed all the time. No sleep-wake cycles present. } \\
\hline & 1 & $\begin{array}{l}\text { All major body functions such as breathing, temperature regulation or blood } \\
\text { pressure can be disturbed. Generally, no reactions are noticed after } \\
\text { stimulation. Sometimes reflexes (stretching or flexing) are observed as a } \\
\text { reaction to strong pain stimuli. No other reactions are present. }\end{array}$ \\
\hline \multirow[t]{7}{*}{$\begin{array}{l}\text { Vegetative } \\
\text { state (VS) }\end{array}$} & \multirow{3}{*}{\multicolumn{2}{|c|}{$\begin{array}{l}\text { The patient shows sleep-wake cycles, but not a proper day-night rhythm. Most of } \\
\text { the body functions are normal. No further ventilation is required for respiration. } \\
\mathbf{2} \text { Very little response (hyporesponsive) } \\
\text { Generally no response after stimulation. Sometimes delayed presentations } \\
\text { of reflexes are observed. }\end{array}$}} \\
\hline & & \\
\hline & & \\
\hline & \multirow[t]{2}{*}{3} & Reflexive state \\
\hline & & $\begin{array}{l}\text { The stimuli often result in massive stretching or startle reactions, without } \\
\text { proper habituation. Sometimes these reactions evolve into massive } \\
\text { flexing responses. Roving eye movements can be observed, without } \\
\text { tracking. Sometimes grimacing occurs after stimulation. }\end{array}$ \\
\hline & \multirow[t]{2}{*}{4} & High active level and/or reactions in stimulated body parts \\
\hline & & $\begin{array}{l}\text { Generally spontaneous undirected movements. Retraction of a limb } \\
\text { following stimulation. Orientation towards a stimulus, without fixating. } \\
\text { Following moving persons or objects, without fixating. }\end{array}$ \\
\hline
\end{tabular}

(Table continued) 
Appendex Table Continued

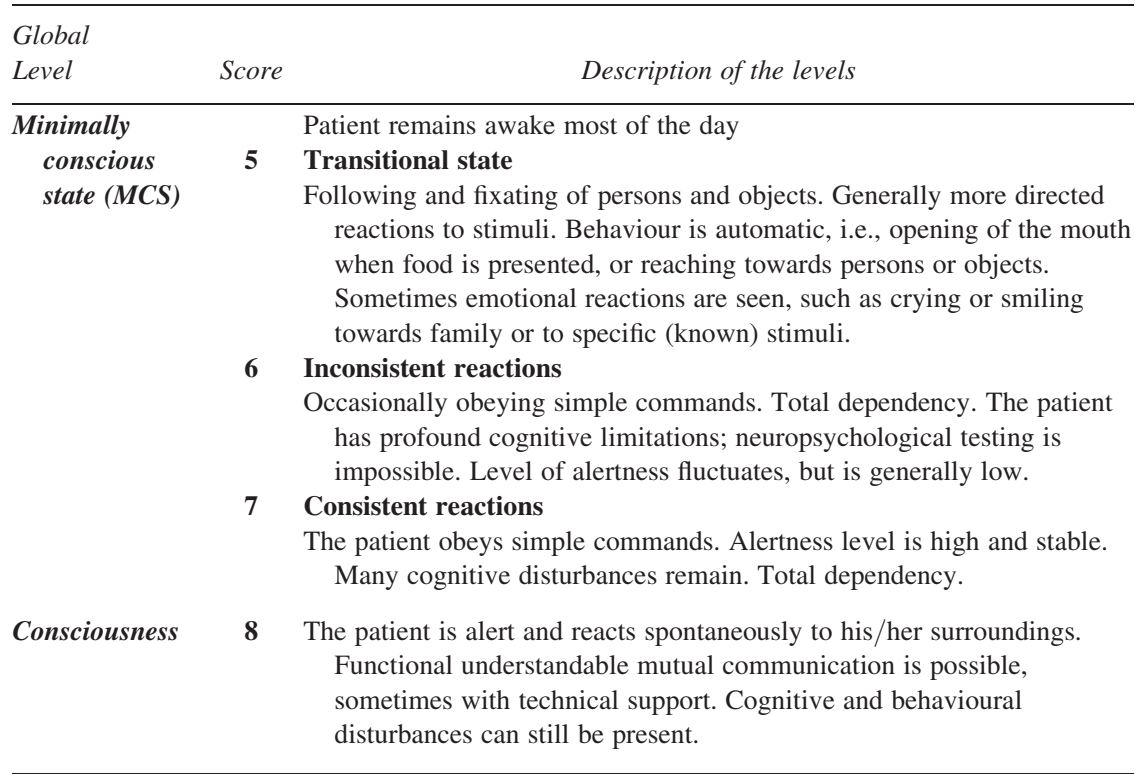

\section{APPENDIX 2}

\section{Examples of changes made in the description of sublevels 6 and 7}

First version PALOC-s

Final version PALOC-s

\section{Inconsistent reactions}

Occasionally obeying simple commands.

Total dependency. The patient has obvious cognitive disturbances and is unable to think comprehensively.

\section{Consistent reactions}

The patient obeys simple commands. Many cognitive disturbances remain. Total dependency.

\section{Inconsistent reactions}

Occasionally obeying simple commands. Total dependency. The patient has profound cognitive limitations; neuropsychological testing is impossible. Level of alertness fuctuates, but is generally low.

\section{Consistent reactions}

The patient obeys simple commands. Alertness level is high and stable. Many cognitive disturbances remain. Total dependency. 